\title{
Hydroxycoumarin Grafted with Hydrazine: Synthesis, Structure Elucidation and Assessment of Antioxidant and Antibacterial Characteristics
}

\author{
Ahmed A. Al-Amiery ${ }^{1, *(D)}$, Lina M. Shaker ${ }^{1}$, Tayser Sumer Gaaz ${ }^{2}$

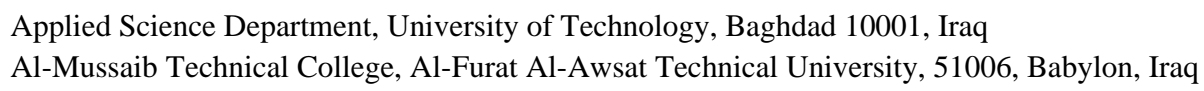

Scopus Author ID 42060956400

Received: 29.09.2020; Revised: 22.10.2020; Accepted: 23.10.2020; Published: 26.10.2020

\begin{abstract}
Hydroxycoumarin, as a natural organic compound, was structurally grafted onto a benzaldehyde by hydrazine. The chemical structure of grafted macromolecule was confirmed by FT-IR and NMR spectroscopy. The antibacterial activity of the synthesized grafted macromolecule against Staphyloccocus aureus, E. coli, Proteus vulgaris, Pseudomonas, and Klebsiella pneumoniae was assessed using a disc diffusion technique. The antioxidant activity of the grafted macromolecule was also highlighted using the superoxide-radical technique. The grafted macromolecule has high inhibition activity against all tested bacteria. The grafted macromolecule was a much more effective free radical scavenger than vitamin $\mathrm{C}$.
\end{abstract}

Keywords: hydrazine; Superoxide-Radical; macromolecule; highlighted; Staphyloccocus.

(C) 2020 by the authors. This article is an open-access article distributed under the terms and conditions of the Creative Commons Attribution (CC BY) license (https://creativecommons.org/licenses/by/4.0/).

\section{Introduction}

Coumarin derivatives were reported to have various medicinal effectiveness [1]. Coumarins were used to remedy such varied diseases as carcinoma, brucellosis, burns, and cardiovascular and rheumatic ailments [2]. The molecule of coumarin has been demonstrated to have significant activities such as anti-inflammatory and antiedema. Therefore, coumarins could be especially efficient in all high protein edemas remediation [3]. Different coumarins are known as the lipoxygenase and cyclooxygenase pathways inhibitors of arachidonate metabolism [4] in addition to superoxide anion generation of neutrophil-dependent [5]. Several coumarins (natural and/or synthetic) with which substituent with different hydroxyl groups had the ability to control or inhibit lipid peroxidation, scavengers for radicals, anion for superoxide, and impact approaches including injury of free radical-mediated [6]. It has been reported that coumarins Schiff bases have a considerable role as medical and pharmaceutical efficient compounds in different diseases [7]. Schiff base is the compound having azomethine $(-\mathrm{C}=\mathrm{N}-$ ) group. This is a reaction condensation product of amine (1) and carbonyl compound and was first published by Hugo Schiff [8]. Schiff bases were a significant type of the most widely utilized organic molecules and had a wide variety of employments in several domains such as analytical, medical, and inorganic chemistry. Schiff bases have acquired significance in pharmaceutical and medical fields, which were imputed to their biological activities such as anti-inflammatory [9], analgesic [10], antibacterial [11], anticonvulsant [12], antitubercular [13], antitumor [14], scavengers [15] and anthelmintic [16]. The imine group in the Schiff base 
molecule has the ability to form a hydrogen bond with the cell constituents' active centers and interferes in processes of normal cells [17]. Continuing published studies on the synthesis of new coumarins [18-41], we found it motivating to synthesize hydroxycoumarin Schiff base, namely " $\mathrm{N}$ '-benzylidene-2-coumarin-4-oxyacetohydrazide "as a possible antibacterial and antioxidant agent. The structure of synthesized grafted macromolecule combines the efficient medicinal group of hydroxycoumarin and the amine moiety as a new template for antibacterial and antioxidant activities.

\section{Materials and Methods}

\subsection{General.}

All chemicals have been supplied by either Fluka or Merck and are used without further purifications. The spectra of Fourier-transform infrared were recorded Shimadzu FTIR Spectrophotometer-8300. The spectra of UV-Vis were recorded on 160A Shimadzu spectrophotometer UV-VIS. NMR spectra were recorded on DPX $300 \mathrm{MHz}$ Brukerspectrometer and use Tetramethylsilane as an internal standard. CHN analysis was conducted on a CHN Erba analyzer model 5500-Carlo.

\subsection{Synthesis of N'-benzylidene-2-coumarin-4-oxyacetohydrazide.}

A mixture of 2-coumarin-4-oxyacetohydrazide ( $0.45 \mathrm{mmol})$ and benzaldehyde $(0.45$ $\mathrm{mmol})$ in ehanol $(50 \mathrm{~mL})$ have been refluxed for 20 hour. The reaction mixture was let to cool. The solid was filtered and recrystallized from ethyl alcohol. Yield 57.0\% and the melting point $258.0^{\circ} \mathrm{C}$. Proton-Nuclear magnetic resonance spectroscopy (Chloroform-d): $8.230 \mathrm{ppm},(1 \mathrm{H}$, singlet, $\mathrm{N}=\mathrm{CH}), 8.110 \mathrm{ppm}(1 \mathrm{H}$, singlet, $\mathrm{N}-\mathrm{H}), \delta 5.340 \mathrm{ppm}$ and $4.910 \mathrm{ppm}\left(2 \mathrm{H}\right.$, singlet, $\left.\mathrm{O}-\mathrm{CH}_{2}\right)$, $5.670(1 \mathrm{H}$, singlet, $-\mathrm{C}=\mathrm{C}-\mathrm{H}), 7.240 \mathrm{ppm}, 7.312 \mathrm{ppm}$ and $7.970 \mathrm{ppm}(1 \mathrm{H}$, singlet, aromatic ring); Nuclear magnetic resonance spectroscopy: (170.0, N-C=O), (169.2, C=C-O), (164.1, $\mathrm{C}=\mathrm{O}),(155.1, \mathrm{C}=\mathrm{C}-\mathrm{O}),(145.6, \mathrm{C}=\mathrm{N}),(136.9,129,8,128,125,120.6,119.9,118.4,118.3,117.9$ and 80.1, aromatic rings) and $\left(65.2, \mathrm{CH}_{2}-\mathrm{O}\right)$; Fourier-transform infrared in $\mathrm{cm}^{-1}: 3191.1$, 2901.0, 3058.2, 1743.3, 1688, 1613 and 1627.7 for N-H, C-Haliphatic, C-H aromatic, lacton, amide, imin and ethylene reciepectiely.

\subsection{Pharmacology: antibacterial activities.}

All test microorganisms were as follows: Escherichia coli, Proteus vulgaris, Klebsiella pneumoniae, Pseudomonas aeruginosa, and Staphylococcus aureus. Antibacterial efficiencies of the synthesized compound were determined by the disc diffusion technique [42]. Whatman no. 4 filter paper discs (6 $\mathrm{mm}$ diameter) were immersed in dimethylformamide solution in the presence examine coumarin of $50-500 \mu \mathrm{g} / \mathrm{ml}$ concentration. The dried discs were placed on nutrient agar plates. The inhibitive zone was evaluated after 24 hours. Dimethylformamide was utilized as a control.

\subsection{Pharmacology: superoxide anion radical-antioxidant efficiency.}

The solutions were:

- Nitro blue tetrazolium solution was prepared by dissolve Nitroblue tetrazolium in phosphate buffer; 
- Phenazine methosulfate solution was prepared by dissolving Phenazine methosulfatein phosphate buffer;

The superoxide anion antioxidant efficiency measurements of grafted macromolecule depended on the technique reported by Chang 2002 [43]. A solution of nitro blue tetrazolium solution $1 \mathrm{~mL}$ and different concentrations $(50,100,150,200,300,500 \mu \mathrm{g} / \mathrm{ml})$ of grafted macromolecule. Added $100 \mu \mathrm{l}$ to the above solution and incubated for 5 minutes at $25^{\circ} \mathrm{C}$ and measure the absorbance at $560 \mathrm{~nm}$. Vitamin $\mathrm{C}$ was utilized as a standard comparing with the tested grafted macromolecule.

\subsection{Statistical analysis.}

Statistical analysis was calculated by utilizing the ANOVA technique. If $P<0.05$ was considered as significant value, whereas $P<0.001$ as excellent value.

\section{Results and Discussion}

\subsection{Chemistry.}

2-coumarin-4-oxyacetohydrazide was refluxed with benzaldehyde in order to synthesis the target $N^{\prime}$-benzylidene-2-coumarin-4-oxyacetohydrazide (Figure 1). The Fouriertransform infrared spectrum (in $\mathrm{cm}^{-1}$ ) of $N^{\prime}$-benzylidene-2-coumarin-4oxyacetohydrazide demonstrated significant bands at 3191.1 for secondary amine 1734.3 for carbonyl of lactone group, 1688 for carbonyl of the amide group. The Proton-Nuclear magnetic resonance spectrum exhibited the absence of protons of the primary amino group and the presence of a new proton of the imin group at $8.23 \mathrm{ppm}$.

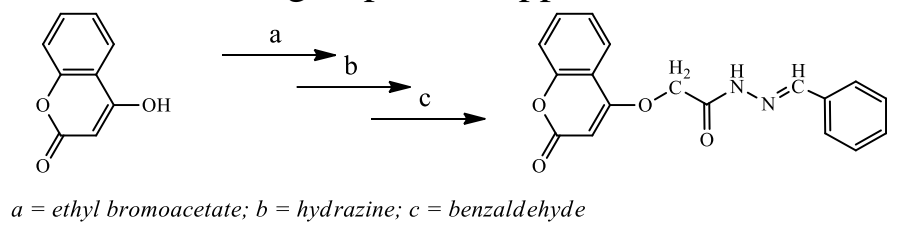

Figure 1. Synthesis of N'-benzylidene-2-coumarin-4-oxyacetohydrazide.

\subsection{Pharmacology: In vitro antibacterial studies.}

The in vitro antibacterial experimental findings are demonstrated in Figure 2. Each experiment has been repeated three times, and the standard error was $\pm 0.1 \mathrm{~mm}$. The negative control which was utilized in all the experiments was dimethylformamide, and the positive standard was chloramphenicol. The experimental findings show that N'-benzylidene-2coumarin-4-oxyacetohydrazide has significant actives against all tested bacteria, as in Figure 2.

According to the experimental findings of the antibacterial investigations, the activity of the examined compound against G+ bacteria was significant and higher than that exhibited for G- bacteria. N'-benzylidene-2-coumarin-4-oxyacetohydrazide was quite efficient active against Staphylococcus aureus. The imine $-\mathrm{C}=\mathrm{N}$ group was correlated with an increased activity versus Staphylococcus aureus. N'-benzylidene-2-coumarin-4-oxyacetohydrazide demonstrated significant antimicrobial performance versus Proteus vulgaris and Klebsiella pneumoniae. Versus E. coli N'-benzylidene-2-coumarin-4-oxyacetohydrazide as the studied compound was a lower performance than the control chloramphenicol. 

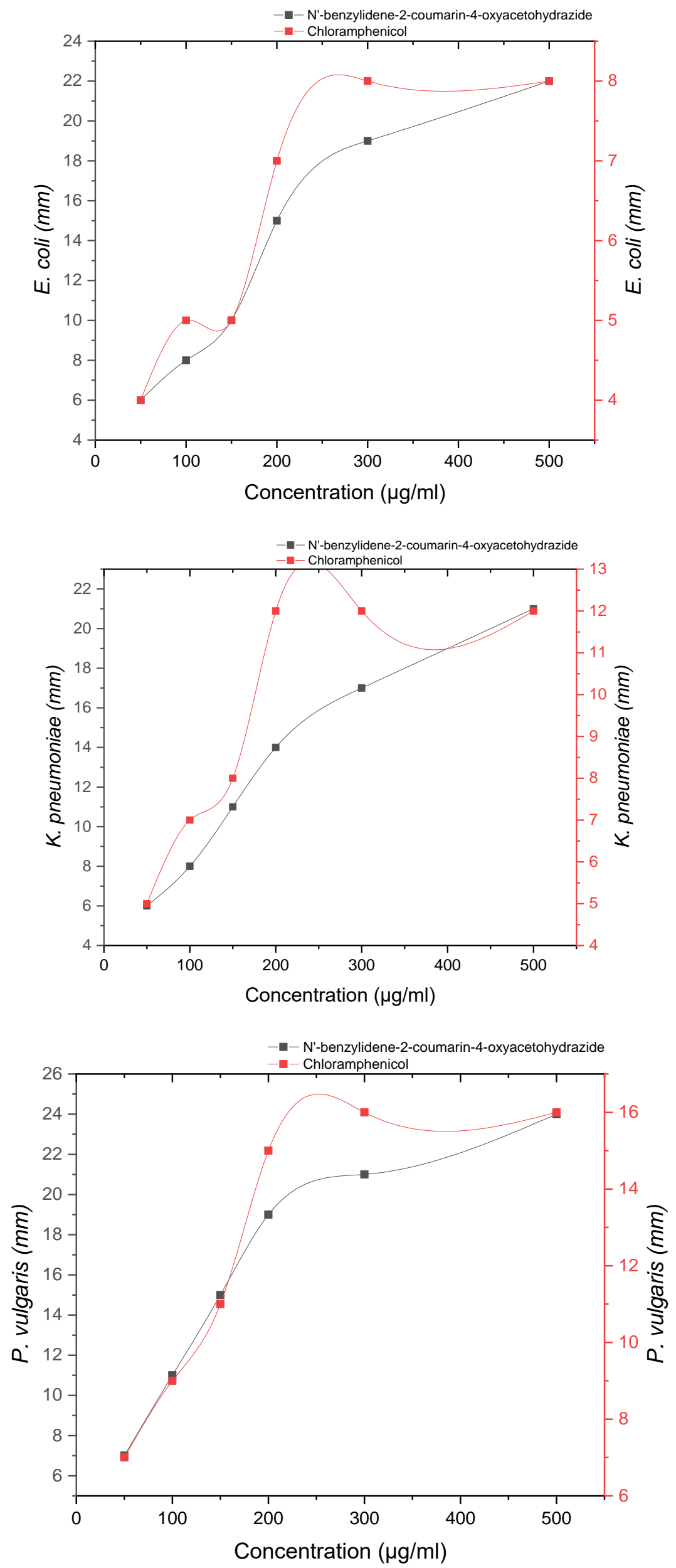

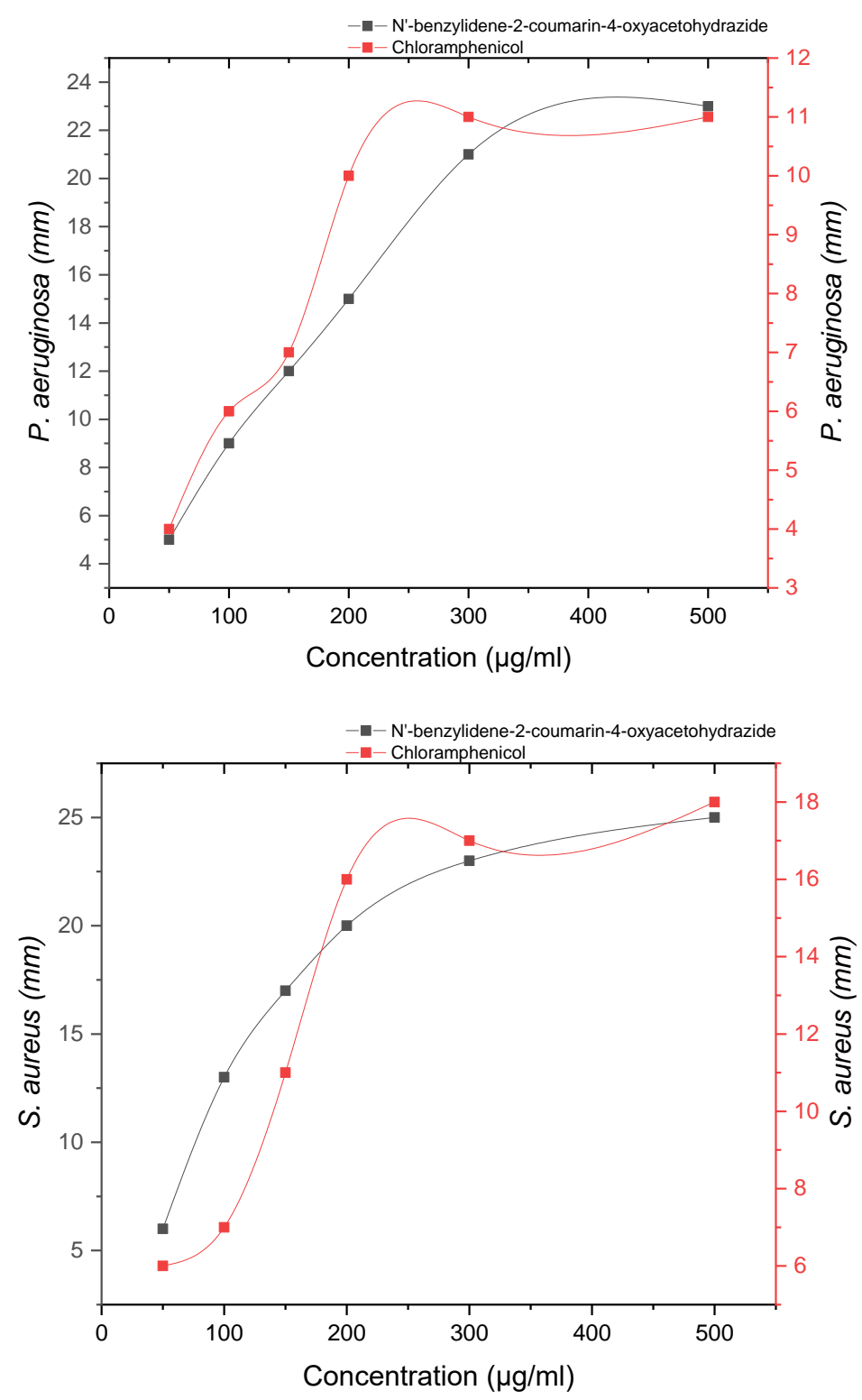

Figure 2. Antibacterial activities of various concentrations N'-benzylidene-2-coumarin-4-oxyacetohydrazide versus chloramphenicol.

\subsection{Pharmacology: superoxide anion radical-antioxidant efficiency.}

Antioxidant compounds are important for humans and animals to protect them from the uncontrolled production of reactive oxygen species and DNA breakdown, which damaged the living organisms. Current attention is concentrated on the antioxidants potential in the remediation, atherosclerosis prevention, failure of heart, disorders of neurodegenerative, aging, tumors, diabetes, and many other diseases [44].

Superoxide anion radical (O2-) is a significant parameter in the bacteria-killing [45]. Signify the exhaustion of superoxide anion in the reaction mixtures. Figure 3 demonstrates the inhibition efficiency of superoxide radical generation by $50,100,150,200,300,500 \mu \mathrm{g} / \mathrm{ml}$ of the N'-benzylidene-2-coumarin-4-oxyacetohydrazide compared with vitamin $\mathrm{C}$. The concentration of the N'-benzylidene-2-coumarin-4-oxyacetohydrazide has a considerable level $(\mathrm{P}<0.001)$ of superoxide radical scavenging efficiency compared with vitamin $\mathrm{C}$. 


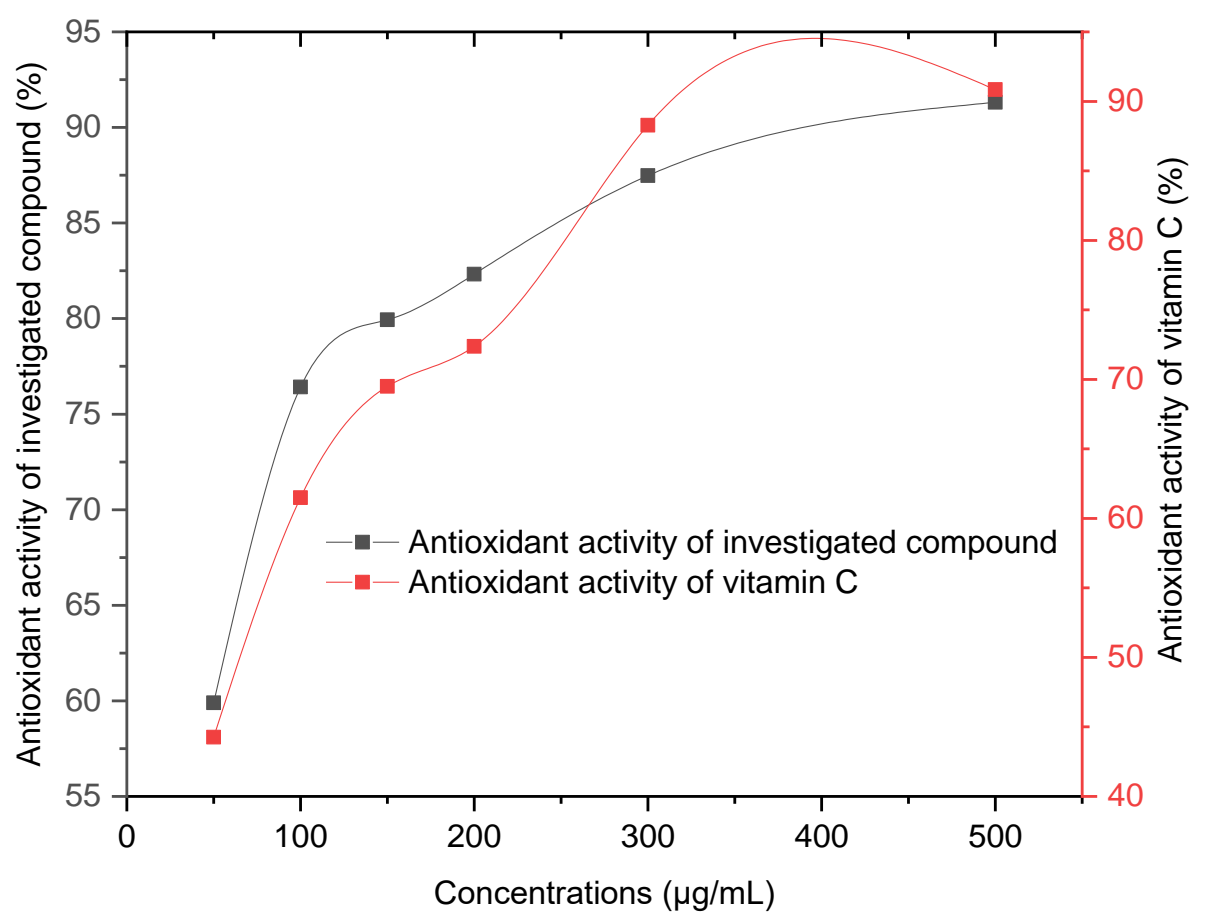

Figure 3. Antioxidant activities of various concentrations N'-benzylidene-2-coumarin-4-oxyacetohydrazide versus vitamin $\mathrm{C}$.

\section{Conclusions}

Hydroxycoumarin grafted with hydrazine was synthesized and fully characterized using the spectroscopical techniques and micro elemental CHN analysis. The antibacterial efficiencies against selected types of bacteria (Staphyloccocus aureus, E. coli, Proteus vulgaris, Pseudomonas, and Klebsiella pneumoniae) indicate that N'-benzylidene-2-coumarin-4oxyacetohydrazide demonstrates significant efficiency as compare with chloramphenicol. The antioxidant activity of the synthesized compound shows that N'-benzylidene-2-coumarin-4oxyacetohydrazide molecules have high scavenging activity against vitamin $\mathrm{C}$.

\section{Funding}

This research received no external funding.

\section{Acknowledgments}

The authors are grateful to the University of Technology/ Baghdad-Iraq for support.

\section{Conflicts of Interest}

The authors declare no conflict of interest.

\section{References}

1. Koleva, A.; Yankova, N.; Nikolova, R.; Synthesis and Chemical Properties of 3-Phosphono-coumarins and 1,2-Benzoxaphosphorins as Precursors for Bioactive Compounds. Molecules 2019, 24, https://doi.org/10.3390/molecules24112030.

2. Foroozesh, M.; Sridhar, J.; Goyal, N.; Liu, J. Coumarins and P450s, Studies Reported to-Date. Molecules 2019, 24, https://doi.org/10.3390/molecules24081620.

3. Bruni, R.; Barreca, D.; Protti, M.; Brighenti, V.; Righetti, L.; Anceschi, L.; Mercolini, L.; Benvenuti, S.; Gattuso, G.; Pellati, F. Botanical Sources, Chemistry, Analysis, and Biological Activity of Furanocoumarins of Pharmaceutical Interest. Molecules 2019, 24, https://doi.org/10.3390/molecules24112163. 
4. Kerekes, D.; Csorba, A.; Gosztola, B.; Németh-Zámbori, É.; Kiss, T.; Csupor, D. Furocoumarin Content of Fennel-Below the Safety Threshold. Molecules 2019, 24, https://doi.org/10.3390/molecules24152844.

5. Ozaki, Y.; Ohashi, T.; Niwa, Y. A comparative study on the effects of inhibitors of the lipoxygenase pathway on neutrophil function. Inhibitory effects on neutrophil function may not be attributed to inhibition of the lipoxygenase pathway. Biochem. Pharmacol. 1986, 35, https://doi.org/10.1016/0006-2952(86)90615-5.

6. Mora, A.; Paya, M.; Rios, J.L.; Alcaraz, M.J. Structure-activity relationships of polymethoxyflavones and other flavonoids as inhibitors of nonenzymic lipid peroxidation. Biochem. Pharmacol. 1990, 40, 793-7, https://doi.org/10.1016/0006-2952(90)90317-E.

7. Da Re, P.; Bonola, G.; Verlicchi, L. A series of Coumarin Derivatives with Central Stimulating Activity. $J$. Med. Chem. 1964, 7, 162-166, https://doi.org/10.1021/jm00332a010.

8. Hussain, A.; AlAjmi, M.F.; Rehman, M.T.; Amir, S.; Husain, F.M.; Alsalme, A.; Siddiqui, M.A.; AlKhedhairy, A.A.; Khan, R.A. Copper(II) complexes as potential anticancer and Nonsteroidal antiinflammatory agents: In vitro and in vivo studies. Sci. Rep. 2019, 9, https://doi.org/10.1038/s41598-01941063-X.

9. Liao, Y.; Zhao, J.; Bulek, K.; Tang, F.; Chen, X.; Cai, G.; Jia, S.; Fox, P.; Huang, E.; Pizarro, T.; Kalady, M.F.; Jackson, M.W.; Bao, S.; Sen, G.C.; Stark, G.R.; Chang, C.J.; Li, X. Inflammation mobilizes copper metabolism to promote colon tumorigenesis via an IL-17-STEAP4-XIAP axis. Nat. Commun. 2020, 11, https://doi.org/10.1038/s41467-020-14698-y.

10. Sukul, A.; Poddar, S.K.; Haque, S.; Kumar, S.; Das, S.; Mahmud, Z.; Rahman, A. Synthesis, Characterization and Comparison of Local Analgesic, Anti-Inflammatory, Anti-Ulcerogenic Activity of Copper and Zinc Complexes of Indomethacin. Anti-Inflamm. Anti-Allergy Agents Med. Chem. 2017, 15, 221-233, https://doi.org/10.2174/1871523016666170217103402.

11. Selvi, G.; Özdemir, F.A.; Aykutoglu, G.; Özdemir, N.; Şerbetçi, Z.; Çetinkaya, B.; Dayan, O. A neutral arene ruthenium(II) complex with a sulfonated N,O-chelating ligand: Synthesis, characterization, in vitro cytotoxicity and antibacterial activity. Polyhedron 2020, 176, https://doi.org/10.1016/j.poly.2019.114300.

12. Abd-Allah, W.H.; Osman, E.E.A.; Anwar, M.A.-E.-M.; Attia, H.N.; El Moghazy, S.M. Design, synthesis and docking studies of novel benzopyrone derivatives as anticonvulsants. Bioorganic Chemistry 2020, 98 , https://doi.org/10.1016/j.bioorg.2020.103738.

13. Cai, G.; Yu, W.; Song, D.; Zhang, W.; Guo, J.; Zhu, J.; Ren, Y.; Kong, L. Discovery of fluorescent coumarinbenzo[b]thiophene 1, 1-dioxide conjugates as mitochondria-targeting antitumor STAT3 inhibitors. European Journal of Medicinal Chemistry 2019, https://doi.org/10.1016/j.ejmech.2019.04.024.

14. Amr, A. .-G.; Mageid, R.E.A.; El-Naggar, M.; M. Naglah, A.; S. Nossier, E.; Elsayed, E.A. Chiral Pyridine3,5-bis- (L-phenylalaninyl-L-leucinyl) Schiff Base Peptides as Potential Anticancer Agents: Design, Synthesis, and Molecular Docking Studies Targeting Lactate Dehydrogenase-A. Molecules 2020, 25, https://doi.org/10.3390/molecules25051096.

15. Warad, I.; Ali, O.; Al Ali, A.; Jaradat, N.A.; Hussein, F.; Abdallah, L.; Al-Zaqri, N.; Alsalme, A.; Alharthi, F.A. Synthesis and Spectral Identification of Three Schiff Bases with a 2-(Piperazin-1-yl)-N-(thiophen-2-yl methylene)ethanamine Moiety Acting as Novel Pancreatic Lipase Inhibitors: Thermal, DFT, Antioxidant, Antibacterial, and Molecular Docking Investigations. Molecules 2020, 25, https://doi.org/10.3390/molecules25092253.

16. Mirza, Z.; Soto, E.R.; Hu, Y.; Nguyen, T.-T.; Koch, D.; Aroian, R.V.; Ostroff, G.R. Anthelmintic Activity of Yeast Particle-Encapsulated Terpenes. Molecules 2020, 25, https://doi.org/10.3390/molecules25132958.

17. Annunziata, F.; Pinna, C.; Dallavalle, S.; Tamborini, L.; Pinto, A. An Overview of Coumarin as a Versatile and Readily Accessible Scaffold with Broad-Ranging Biological Activities. International Journal of Molecular Sciences 2020, 21, https://doi.org/10.3390/ijms21134618.

18. Zinad, D.; Hanoon, M.; Dawood, R.; Ibrahim, S.; Al-Amiery, A.; Takriff, M.; Kadhum, A. A new synthesized coumarin-derived Schiff base as a corrosion inhibitor of mild steel surface in $\mathrm{HCl}$ medium: gravimetric and DFT studies. International Journal of Corrosion and Scale Inhibition 2020, 9, 228-243, https://doi.org/10.17675/2305-6894-2020-9-1-14.

19. Zinad, D.; Jawad, Q.; Mahmood, M.; Mahal, A.; Mohamed, 1.; Al-Amiery, A. Adsorption, temperature and corrosion inhibition studies of a coumarin derivatives corrosion inhibitor for mild steel in acidic medium: gravimetric and theoretical investigations. Int. J. Corros. Scale Inhib. 2020, 9, 134-151, https://doi.org/10.17675/2305-6894-2020-9-1-8.

20. AL-Duhaidahawi, D.L.; Al-Majedy, Y.K.; Ibraheem, H.H.; Kadhum, A.A.H.; Al-Amiery, A.A. Macro coumarins as novel antioxidants. Oriental Journal of Chemistry 2018, 34, 2562-2569, http://dx.doi.org/10.13005/ojc/340544.

21. Al-Azawi, K.F.; Al-Baghdadi, S.B.; Mohamed, A.Z.; Al-Amiery, A.A.; Abed, T.K.; Mohammed, S.A.; Kadhum, A.A.H.; Mohamad, A.B. Synthesis, inhibition effects and quantum chemical studies of a novel coumarin derivative on the corrosion of mild steel in a hydrochloric acid solution. Chemistry Central Journal 2016, 10, https://doi.org/10.1186/s13065-016-0170-3. 
22. Al-Amiery, A.A.; Al-Majedy, Y.K.; Kadhum, A.A.H.; Mohamad, A.B. Synthesis of new coumarins complemented by quantum chemical studies. Research on Chemical Intermediates 2016, 42, 3905-3918, https://doi.org/10.1007/s11164-015-2252-6.

23. Al-Majedy, Y.K.; Al-Duhaidahawi, D.L.; Al-Azawi, K.F.; Al-Amiery, A.A.; Kadhum, A.A.H.; Mohamad, A.B. Coumarins as potential antioxidant agents complemented with suggested mechanisms and approved by molecular modeling studies. Molecules 2016, 21, https://doi.org/10.3390/molecules21020135.

24. Al-Majedy, Y.K.; Kadhum, A.A.H.; Al-Amiery, A.A.; Mohamad, A.B. Coumarins: The antimicrobial agents. Systematic Reviews in Pharmacy. 2016, 8, 62-70.

25. Al-Majedy, Y.; Al-Amiery, A.; Kadhum, A.A.; Bakar Mohamad, A. Antioxidant activity of coumarins. Systematic Reviews in Pharmacy, 2016, 8, 24-30.

26. Issa, A.Y.; Rida, K.S.; Salam, A.Q.; Al-Amiery, A.A. Acetamidocoumarin as a based eco-friendly corrosion inhibitor. International Journal of ChemTech Research, 2016, 9, 39-47.

27. Al-Amiery, A.A.; Al-Majedy, Y.K.; Kadhum, A.A.H.; Mohamad, A.B. Hydrogen peroxide scavenging activity of novel coumarins synthesized using different approaches. PLoS ONE, 2015, 10, https://doi.org/10.1371/journal.pone.0132175.

28. Al-Amiery, A.A.; Al-Majedy, Y.K.; Kadhum, A.A.H.; Mohamad, A.B. Novel macromolecules derived from coumarin: Synthesis and antioxidant activity. Scientific Reports 2015, 5, https://doi.org/10.1038/srep11825.

29. Al-Amiery, A.A.; Musa, A.Y.; Kadhum, A.A.H.; Mohamad, A.B. The Use of Umbelliferone in the Synthesis of New Heterocyclic Compounds. Molecules 2011, 16, 6833-6843, https://doi.org/10.3390/molecules16086833.

30. Al-Amiery, A.A.; Al-Majedy, Y.K.; Kadhum, A.A.H.; Mohamad, A.B. New Coumarin Derivative as an Eco-Friendly Inhibitor of Corrosion of Mild Steel in Acid Medium. Molecules 2015, 20, 366-383, https://doi.org/10.3390/molecules20010366.

31. Al-Majedy, Y.K.; Kadhum, A.A.H.; Al-Amiery, A.A.; Mohamad, A.B. Synthesis and characterization of some new 4-hydroxycoumarin derivatives. Molecules 2014, 19, 11791-11799, https://doi.org/10.3390/molecules190811791.

32. Kadhum, A.A.H.; Mohamad, A.B.; Hammed, L.A.; Al-Amiery, A.A.; San, N.H.; Musa, A.Y. Inhibition of Mild Steel Corrosion in Hydrochloric Acid Solution by New Coumarin. Materials 2014, 7, 4335-4348, https://doi.org/10.3390/ma7064335.

33. Mohamad, A.B.; Kadhum, A.A.H.; Al-Amiery, A.A.; Ying, L.C.; Musa, A.Y. Synergistic of a coumarin derivative with potassium iodide on the corrosion inhibition of aluminum alloy in 1.0 M H2SO4. Metals and Materials International 2014, 20, 459-467, https://doi.org/10.1007/s12540-014-3008-3.

34. Kadhum, A.A.H.; Mohamad, A.B.; Hammed, L.A.; Al-Amiery, A.A.; San, N.H.; Musa, A.Y. Inhibition of mild steel corrosion in hydrochloric acid solution by new coumarin. Materials 2014, 7, 4335-4348, https://doi.org/10.3390/ma7064335.

35. Mohamad, A.B.; Kadhum, A.A.H.; Al-Amiery, A.A.; Ying, L.C.; Musa, A.Y. Synergistic of a coumarin derivative with potassium iodide on the corrosion inhibition of aluminum alloy in $1.0 \mathrm{M} \mathrm{H} 2 \mathrm{SO}$. Metals and Materials International 2014, 20, 459-467, https://doi.org/10.1007/s12540-014-3008-3.

36. Al-Amiery, A.A.; Kadhum, A.A.H.; Al-Majedy, Y.K.; Ibraheem, H.H.; Al-Temimi, A.A.; Al-Bayati, R.I.; Mohamad, A.B. The legend of 4-aminocoumarin: Use of the Delépine reaction for synthesis of 4iminocoumarin. Research on Chemical Intermediates 2013, 39, 1385-1391, https://doi.org/10.1007/s11164012-0694-7.

37. Al-Amiery, A.A.; Al-Bayati, R.I.H.; Saour, K.Y.; Radi, M.F. Cytotoxicity, antioxidant, and antimicrobial activities of novel 2-quinolone derivatives derived from coumarin. Research on Chemical Intermediates 2012, 38, 559-569, https://doi.org/10.1007/s11164-011-0371-2.

38. Al-Amiery, A.A.; Kadhum, A.A.H.; Mohamad, A.B. Antifungal activities of new coumarins. Molecules 2012, 17, 5713-5723, https://doi.org/10.3390/molecules17055713.

39. Al-Amiery, A.A.; Jaffar, H.D.; Obayes, H.R.; Musa, A.Y.; Kadhum, A.A.H.; Mohamad, A.B. Thermodynamic studies on 4-aminocoumarin tautomers. International Journal of Electrochemical Science 2012, 7, 8468-8472.

40. Kadhum, A.A.H.; Al-Amiery, A.A.; Musa, A.Y.; Mohamad, A.B. The antioxidant activity of new coumarin derivatives. International Journal of Molecular Sciences 2011, 12, 5747-5761, https://doi.org/10.3390/ijms12095747.

41. Kadhum, A.A.H.; Mohamad, A.B.; Al-Amiery, A.A.; Takriff, M.S. Antimicrobial and antioxidant activities of new metal complexes derived from 3-aminocoumarin. Molecules 2011, 16, 6969-6984, https://doi.org/10.3390/molecules16086969.

42. Al-Amiery, A.; Al-Majedy, Y.; Abdulreazak, H.; Abood, H. Synthesis, Characterization, Theoretical Crystal Structure, and Antibacterial Activities of Some Transition Metal Complexes of the Thiosemicarbazone (Z)2-(pyrrolidin-2-ylidene)hydrazinecarbothioamide. Bioinorganic Chemistry and Applications 2011, 2011, https://doi.org/10.1155/2011/483101.

43. Fernández-Bedmar, Z.; Demyda-Peyrás, S.; Merinas-Amo, T.; Del Río-Celestino, M. Nutraceutic potential of two allium species and their distinctive organosulfur compounds: A multi-assay evaluation. Foods 2019, 8, https://doi.org/10.3390/foods8060222. 
44. Aires, V.; Labbé, J.; Deckert, V.; Pais de Barros, J.-P.; Boidot, R.; Haumont, M.; Maquart, G.; Le Guern, N.; Masson, D.; Prost-Camus, E.; Prost, M.; Lagrost, L. Healthy adiposity and extended lifespan in obese mice fed a diet supplemented with a polyphenol-rich plant extract. Scientific Reports 2019, 9, 9134, https://doi.org/10.1038/s41598-019-45600-6.

45. Souza-Monteiro, J.; Arrifano, G.; Gois, I.; Mello, B.; Custódio, C.; Macedo, D.; Hamoy, M.; Paraense, R.; Bittencourt, L.; Lima, R.; Burbano, R.; Rogez, H.; Maia, C.; Macchi, B.; Nascimento, J.; Crespo-López, M. Antidepressant and Antiaging Effects of Açaí ( Euterpe oleracea Mart.) in Mice. Oxidative Medicine and Cellular Longevity 2019, 2019, 1-16, https://doi.org/10.1155/2019/3614960. 